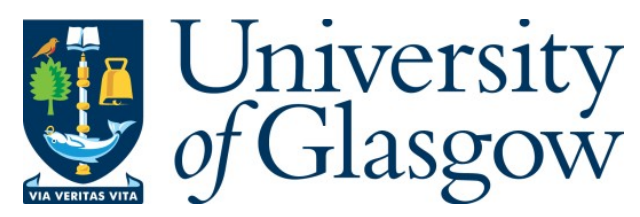

Hartley, K., Lim, N. S. W. and Tortajada, C. (2021) Policy note: Digital feedback-based interventions for water conservation. Water Economics and Policy, 7(1), 2071004.

(doi: 10.1142/S2382624X20710046)

This is the Author Accepted Manuscript.

There may be differences between this version and the published version. You are advised to consult the publisher's version if you wish to cite from it.

https://eprints.gla.ac.uk/234961/

Deposited on: 24 February 2021

Enlighten - Research publications by members of the University of Glasgow http://eprints.gla.ac.uk 


\title{
Digital Feedback-Based Interventions for Water Conservation
}

Kris Hartley, Education University of Hong Kong, Department of Asian and Policy Studies

Nicole Lim Sher Wen, National University of Singapore, Department of Psychology

Cecilia Tortajada, University of Glasgow, School of Interdisciplinary Studies

Published in Water Economics and Policy (2021)

https://doi.org/10.1142/S2382624X20710046

\begin{abstract}
Progress in water conservation is dependent as much on human behavior as on the promise of new technologies. Digital feedback-based interventions present an opportunity to bring these two factors together, as increasingly sophisticated technologies can help change behaviors rather than simply solving problems caused by those behaviors. This article explores the various options and opportunities for adopting feedback-based interventions - those that communicate information for the purpose of encouraging individuals to alter water consumption habits. Lessons proposed are applicable to any realm in which individual human behavior contributes to a collective environmental or social problem. Focusing on five determinants of success (design, delivery, content, integration, and commitment), this article presents findings of related studies and fashions them into a suite of recommendations that serves as a template for practice and agenda for future research. The underlying theme - that technology is no absolute substitute for behavioral change but can be one catalyst for it - contributes to broader discussions about the relationship between human systems and the environment.
\end{abstract}

Keywords: smart water management; digital feedback; water conservation; sustainability; public policy

\section{Introduction}

A feedback-based intervention is a mechanism that seeks to alter habitual or ingrained behaviors through the targeted provision of information. As habits are often the by-products of "learned cue-behavior associations" (Wood and Neal, 2009) prompted by environmental stimuli, feedback-based interventions seek to arrest counterproductive habits through information-based cues. These interventions operate through the collection of relevant information about an individual's behavior, translation of that information in a way that is legible and meaningful to the individual, and communication of the results in a timely and appropriately frequent manner. 
Feedback by physical means to encourage pro-social or pro-environmental behavior is typically direct (in-person) or indirect (e.g., posters, pamphlets, and other types of public communications). Collecting information to personalize direct feedback at scale can require substantial time and effort to coordinate and execute (Hermsen et al., 2016). Feedback communicated indirectly, by comparison, is limited in its targeting precision (Quinn et al., 2010).

These constraints have inspired the adoption and novel application of digital technologies, which have the potential to revolutionize feedback-based interventions and circumvent the limitations of traditional data collection methods and feedback delivery mechanisms (Hermsen et al., 2016). Technologies such as 'smart' sensors and wearable devices enable data to be collected and processed in real-time with high detail. An example is the use of tracking wristbands for individuals serving COVID-19 quarantine in Hong Kong. ${ }^{1}$ These exemplify the type of personal data-collection capacity that is being adopted for measuring consumption patterns in public utility services (e.g., water and energy). Regarding feedback, mobile applications and digital dashboards offer novel ways to personalize and instantaneously deliver messages with high frequency over long periods of time; additionally, fewer resources are required than with alternative (non-digital) methods.

These types of technologies can be broadly termed 'digital feedback-based interventions' (hereafter, 'digital interventions') - systems that enable utility service providers to communicate consumption information in real-time through online portals, text messages, email, social media, and digital read-outs on appliances. This feedback can include not only individual user and household data but also that data in combination with broader information contextualizing or comparing the target user's behavior to that of others; the typical objective is to encourage the user to alter behavior in a way that is socially or environmentally optimal.

With the ability to gather, analyze, and communicate detailed data on a scalable basis, digital interventions have the potential not only to influence individual behavior but also to economize and personalize utility services and ultimately serve broader goals related to sustainability. Recognition among water experts and professionals about this potential is described in a quote by Hartley and Kuecker (2020): "policy actors, after years of refining it through digital transformation, increasingly embrace [smart water management] as a tool for facilitating integrated water resources management across manifold policy domains including sourcing, delivery, quality, and resilience amidst external threats like floods and droughts. Policy actors see [smart water management] also as a pathway towards broader social, economic, environmental, and governance objectives, as consistent with the visions of the United Nations Sustainable Development Goals" (p. 1-2).

\footnotetext{
1 https://www.coronavirus.gov.hk/eng/stay-homesafe.htm|\#: :text=If\%20you\%20are\%20subject\%20to,to\%20put\%20on\%20a\%20wristband.\&text=Upon\% 20arrival\%20at\%20Hong\%20Kong,Government\%20after\%20you\%20return\%20home. (accessed 28 Aug 2020)
} 
In exploring the potential for digital feedback to help support the broader smart water management agenda, this article proceeds with an overview of its use in water conservation and offers an analysis of best practices across five determinants of successful intervention: design, delivery, content, integration, and commitment.

\section{Digital feedback in water conservation}

The post-drought experiences of Cape Town (Rodina, 2019) and São Paulo (Braga and Kelman, 2020) illustrate how water conservation behaviors can be shaped into durable and sustained habits. Such efforts require the coordination of policy interventions, messaging, and incentives. Conversely, wasteful consumption habits can, amidst weakly coordinated or absent feedback, become ingrained as individuals fail to realize the extent or consequences of their actions. Even when information is available, some individuals may still not connect evidence of wastefulness with their own habits or may lack the knowledge and will for corrective action.

Studies show that digital interventions can be an efficient means for collecting data about and communicating with water users - including the management of large amounts of information at a broad scale (Konopko, 2016; Rathore et al., 2016; Mudumbe and Abu-Mahfouz, 2015; Gurung et al., 2014; Benzi et al., 2011). An example of such technology is 'smart' water meters, which monitor consumption patterns, process data, and communicate information in real-time (Owen, 2018; Monks et al., 2019; Cominola et al., 2015). With this capability, water utilities are able to provide near-instantaneous feedback to households about water consumption - for example, through online portals and mobile applications. Further, this process can be automated to reduce resource needs and increase efficiency. The flexible nature of digital platforms also enables feedback to be presented in innovative, interactive, and meaningful ways; an example is 'gamifying' individual consumption through comparisons among households (Johnson et al., 2017; Morganti et al., 2017). Digital interventions at the individual or household level are scalable in that they can be replicated and distributed through technologies that already exist in homes (e.g., smart meters) or are owned by users (e.g., smartphones).

Water demand management research has generally been mixed to marginally positive in its evaluation of the efficacy of digital interventions in changing utilities' consumption behavior. A meta-analysis conducted by Hermsen et al. (2016) revealed that the majority of 72 analyzed studies demonstrated the efficacy of digital interventions for water consumption. By contrast, an analysis examining 27 studies of energy consumption (Chatzigeorgiou and Andreou, 2021) was unable to determine an average savings effect for digital interventions and found that effect sizes demonstrated a wide variance. A review of 25 studies by Liu and Mukheibir (2018) identified ranges of water savings across both digital and non-digital interventions; online portals (including options to receive alert messages) accounted for the upper end of the range (3 percent 
to 10 percent) and in-home displays the lower end ( 4 percent to 8.5 percent). The Liu and Mukheibir (2018) survey also found that real-time or near-real-time data, for which digital capacity is typically needed, produced a water savings range of 4 percent to 10 percent. The authors conclude that there is no single type of intervention that excels above the rest, and that water utilities should proceed with the 'most appropriate' type for the situation. ${ }^{2}$

Measurements of efficacy cast in terms of benefits and costs (Cominola et al., 2015) vary across types of digital interventions. For example, a study by Nauges and Whittington (2019) found that 'social norms information treatments' allowing consumers to compare their usage patterns with those of other users yielded a benefit-cost ratio of 0.9 in low- and middle-income countries and 0.7 in high-income countries (both ratios were lower than those for tariff increases). Regarding the measurement of benefits specifically, MacRae Jr. and Whittington (1988) recognize that such measurements account for social perceptions and preferences - stated or revealed - with implications for the kinds of tools and methods included (or excluded) in policy analysis.

Providing another systematic review of studies concerning the relationship between digital feedback and water consumption is beyond the scope of this discussion. Existing review studies are sufficient bases to accept that digital interventions have shown some positive potential, but results vary across studies based on intervention type (i.e., digital or non-digital), context, and other factors. Even in the absence of such certitude, the efficacy of digital interventions can be inferred from studies about the efficacy of non-digital interventions that can be extended and optimized through technology. Indeed, efforts to provide information in non-digital ways (e.g., through paper reports) have generally proven to encourage water savings (Legault et al., 2018; Brick et al., 2017; Schultz et al., 2016; Brent et al., 2015; Datta et al., 2015; Ferraro and Price, 2013; Kenney et al., 2008; Kurz et al., 2005).

Based on the above findings, digital interventions that take the same underlying approach as successful non-digital interventions (e.g., comparisons and 'gamification') should invite policy interest - particularly for technologies that appear to play a central role in users' everyday lives. For example, Chatzigeorgiou and Andreou (2021) argue that "mobile phones [are] a promising platform for further [digital intervention] research, as these exhibit an increasing level of integration in users' everyday life" (p. 14). Indeed, there is potential for digital interventions to influence water consumers as non-digital alternatives become anachronistic over time and thus less effective. As such, this article aims to provide insight into the optimal, standardized, and scalable utilization of digital interventions for water demand management. The remaining discussion of best practices is predicated on the cautiously optimistic notion that digital

${ }^{2}$ According to Liu and Mukheibir (2018), the efficacy of selected non-digital interventions was not found to be notably lower than that of digital interventions; examples of the former include post cards (7.9 percent savings) and letters/phone calls (6.9 percent). 
interventions can be as effective as, or more effective than, non-digital interventions recognizing that further research is still needed.

\section{Best practices for digital interventions}

This section provides a summary of best practices for maximizing the impact of digital interventions, organized into five determinants of success: design, delivery, content, integration, and commitment. These determinants, sub-areas (if any), descriptions, and best practices are summarized in Table 1.

Table 1: Five determinants of successful digital interventions

\begin{tabular}{|c|l|l|l|}
\hline \multicolumn{1}{|c|}{ Area } & \multicolumn{1}{|c|}{ Sub-Area } & \multicolumn{1}{|c|}{ Description } & \multicolumn{1}{c|}{ Best Practice } \\
\hline Design & $\begin{array}{l}\text { Technology } \\
\text { channel }\end{array}$ & $\begin{array}{l}\text { Type of technology used (e.g., } \\
\text { mobile phone app, digital display) }\end{array}$ & $\begin{array}{l}\text { No best practice; dependent on } \\
\text { individual preference* }\end{array}$ \\
\cline { 2 - 5 } & $\begin{array}{l}\text { Feedback } \\
\text { modality }\end{array}$ & $\begin{array}{l}\text { Visual, auditory, tactile, or } \\
\text { combination used to deliver } \\
\text { feedback }\end{array}$ & $\begin{array}{l}\text { Determine modality based on } \\
\text { extent of disruption and/or detail } \\
\text { of message desired }\end{array}$ \\
\cline { 2 - 5 } & User experience & $\begin{array}{l}\text { Visual design and usability; ease } \\
\text { of understanding feedback }\end{array}$ & $\begin{array}{l}\text { Designs should be user-friendly, } \\
\text { intuitive, and aligned with the } \\
\text { intent of the intervention }\end{array}$ \\
\hline \multirow{2}{*}{ Delivery } & Timeliness & $\begin{array}{l}\text { How soon feedback is delivered } \\
\text { after behavior is performed (i.e., } \\
\text { delayed or concurrent) }\end{array}$ & $\begin{array}{l}\text { Convey feedback in real-time } \\
\text { where possible and feasible** }\end{array}$ \\
\cline { 2 - 5 } & Frequency & $\begin{array}{l}\text { How many times feedback is } \\
\text { delivered within a certain } \\
\text { timeframe }\end{array}$ & $\begin{array}{l}\text { No best practice; set frequency } \\
\text { high enough for user engagement }\end{array}$ \\
\cline { 2 - 5 } & $\begin{array}{l}\text { Disruptive- } \\
\text { ness }\end{array}$ & $\begin{array}{l}\text { Period between first and last } \\
\text { feedback delivery }\end{array}$ & $\begin{array}{l}\text { Extend duration of the } \\
\text { intervention for as long as } \\
\text { possible, assuming continued } \\
\text { efficacy, for the cultivation of } \\
\text { long-term habits*** }\end{array}$ \\
\cline { 2 - 5 } & & $\begin{array}{l}\text { No best practice; manage } \\
\text { disruption levels so that user } \\
\text { remains receptive to intervention }\end{array}$ \\
\hline
\end{tabular}




\begin{tabular}{|c|c|c|c|}
\hline \multirow[t]{3}{*}{ Content } & Feedback sign & $\begin{array}{l}\text { Whether the feedback is framed } \\
\text { positively or negatively }\end{array}$ & $\begin{array}{l}\text { Sign based on conditions and } \\
\text { historical efficacy in given } \\
\text { context; positive for new } \\
\text { systems, negative for older } \\
\text { systems }\end{array}$ \\
\hline & $\begin{array}{l}\text { Information } \\
\text { provision }\end{array}$ & $\begin{array}{l}\text { Extent to which feedback } \\
\text { comprises only information about } \\
\text { water consumption behavior }\end{array}$ & $\begin{array}{l}\text { Supplement with other methods } \\
\text { of conveying information (e.g., } \\
\text { feedback comparison) }\end{array}$ \\
\hline & Personalization & $\begin{array}{l}\text { Extent to which feedback is } \\
\text { tailored to individual's } \\
\text { characteristics and preferences } \\
\text { and to the targeted behavior; self- } \\
\text { comparison with historic data }\end{array}$ & $\begin{array}{l}\text { Personalize feedback as much as } \\
\text { possible }\end{array}$ \\
\hline \multirow[t]{2}{*}{ Integration } & Lifestyle & $\begin{array}{l}\text { Extent to which feedback is } \\
\text { integrated into other aspects of an } \\
\text { individual's lifestyle (e.g., } \\
\text { appliances, social media, signage) }\end{array}$ & $\begin{array}{l}\text { Provide additional conduits for } \\
\text { feedback across various } \\
\text { intervention types }\end{array}$ \\
\hline & $\begin{array}{l}\text { Other } \\
\text { intervention }\end{array}$ & $\begin{array}{l}\text { Extent to which feedback is used } \\
\text { in conjunction with other forms } \\
\text { of behavior change interventions }\end{array}$ & $\begin{array}{l}\text { No best practice; consider } \\
\text { combining various types of } \\
\text { feedback-based interventions }\end{array}$ \\
\hline \multicolumn{2}{|c|}{ Commitment } & $\begin{array}{l}\text { Extent to which individuals are } \\
\text { engaged and able to demonstrate } \\
\text { sustained commitment to } \\
\text { behavior the intervention suggests }\end{array}$ & $\begin{array}{l}\text { Prepare engagement strategy to } \\
\text { ensure long-term commitment } \\
\text { and motivation }\end{array}$ \\
\hline \multicolumn{4}{|c|}{$\begin{array}{l}\text { *See Liu and Mukheibir (2018; Table } 1) \text { for relative percentage savings across digital and non-digital } \\
\text { feedback (e.g., in-home displays, online portals, paper displays, and smartphone apps) (0 percent to } 10 \\
\text { percent) } \\
\text { **See Liu and Mukheibir ( } 2018 \text {; Table } 1) \text { for relative percentage savings across communication } \\
\text { frequencies ( } 2.8 \text { percent to } 24.1 \text { percent) } \\
\text { ***See Liu and Mukheibir (2018; Table } 1 \text { ) for relative percentage savings across intervention duration } \\
\text { lengths ( } 4 \text { percent to } 8.5 \text { percent) }\end{array}$} \\
\hline
\end{tabular}




\subsection{Design}

\subsubsection{Technology channel}

Design in this instance refers to elements of technological design that underlie feedback content and delivery, as categorized into three sub-areas: technology channel, feedback modality, and user experience. First, choice of technology channel shapes intervention type in that each channel has characteristics that limit or enable how feedback is designed and delivered. For example, feedback sent via text message can be effective but also limited in both timeliness (i.e., how soon feedback is received after the behavior is performed) and content volume (i.e., restricted to character limits based on mobile carriers' SMS restrictions; Hall et al., 2015).

There is no study that experimentally compares the efficacy of technology channels, according to the meta-analysis conducted by Hermsen et al. (2016). Efforts by Liu and Mukheibir (2018) to compare results of studies based on choice of intervention type (e.g., paper, digital portal, combination) confirmed findings from Hermsen et al. (2016) that technology channel type has no association with efficacy, despite its impact on design and delivery of the intervention. Though underlying other factors that constitute an intervention (e.g., content and delivery), technology channel choice may itself be overshadowed.

\subsubsection{Feedback modality}

Modality, a subset of technology channel, refers to method of feedback delivery: visual, auditory, tactile, or a combination of the three. Like choice of technology channel, each modality has unique characteristics. Individually, the three main modalities can be evaluated on levels of detail and disruptiveness. According to research on feedback modality (Quintal et al., 2012; Warnock et al., 2011; Hoggan and Brewster, 2010; Hoggan et al., 2009; Braverman, 2008; Lieberman and Breazeal, 2007), visual feedback has the highest capacity for providing detailed information but is also the most disruptive with regard to recipient experience. Tactile feedback lacks detail but is the least disruptive, while auditory feedback falls between the two on both spectrums.

There is scant research comparing the three as feedback-based interventions. However, multimodal feedback - the use of multiple modalities concurrently - has been shown more effective for influencing behavior than has single-modality feedback (Quintal et al., 2012; Hoggan and Brewster, 2010; Lieberman and Breazeal, 2007). Though yet to be examined in the context of water consumption, each modality is thought to hold relative benefits in supporting behavior change. For example, in noisy settings, tactile feedback in smartphones catches user attention better than does auditory feedback; vice-versa in quiet settings (Hermsen et al., 2016). 


\subsubsection{User experience}

User experience refers to the experience of the individual receiving and interacting with feedback, broadly encompassing appearance, understandability, and ease of use. More broadly, it refers to user comfort. Examples include the incorporation of charts or games, information that is eye-catching amidst other details, and subtle cues that are intended to shape perception (e.g., professionalism and intuitiveness of the interface). Research has shown that user experience impacts the efficacy of an intervention. For factors like website appearance and typography, visual design can shape a user's attitude towards the behavior intended by the feedback (Tuch et al., 2012; Larson and Picard, 2005; Tractinsky et al., 2000). Attitudes also determine the extent to which interventions shape mindsets and behaviors, so it is crucial to ensure that individuals perceive the feedback favorably. Relatedly, studies reveal that the frequency with which proenvironmental behaviors are performed is positively correlated with ease of completion (Fujii, 2006). As such, feedback-based interventions should be as understandable and actionable as possible.

How to ensure optimal user experience is less clear. Consolvo et al. (2009) suggest that an intervention be aesthetically pleasing, unobtrusive, and comprehensive. Designing for usability and understandability, even at the expense of pure aesthetics, is likewise suggested (Nakajima and Lehdonvirta, 2013; Rodgers and Bartram, 2011), and individuals were found to prefer a visual appearance that matches the intended purpose of the channel (O'Kane et al., 2015). Studies of feedback-based interventions for water demand management specifically have identified elements that enhance user experience. For example, as a blunt heuristic, more information is generally better but there are limits. The provision of consumption data disaggregated by appliance, along with frequent and detailed feedback, is found more effective (Sonderlund et al., 2016; Erickson et al., 2013; Froehlich et al., 2010). However, increased amounts of information provided can compromise understandability and usability. Care must be taken not to alienate, distract, or overwhelm the targeted individual with excessive amounts of data. Regarding presentation, simplicity and clarity were reported to contribute to the influence of graphs as sources of information (Sonderlund et al., 2016).

\subsection{Delivery}

\subsubsection{Feedback timeliness}

Delivery relates to time-related factors for how data are communicated to users, as categorized into feedback timeliness, frequency, and duration. Feedback timeliness refers to the speed with which feedback is delivered after a behavior has been performed. Delayed feedback occurs within a certain period after the behavior and/or its consequence have occurred, while concurrent feedback occurs in real-time as the behavior occurs or immediately thereafter. Generally, 
concurrent feedback is more effective, as immediacy supports better and faster learning regarding cause-effect relationships (Ehrhardt-Martinez et al., 2010; Froehlich et al., 2010). In some cases, concurrent feedback also provides the individual an opportunity to immediately revise the undesired behavior. For example, studies of electricity consumption show greater efficacy of feedback provided in near real-time as compared to feedback delayed (Darby, 2006).

Digital interventions can support delivery of timely feedback, including feedback delivered to large target groups in a resource-efficient manner, but this is dependent on choice of technology channel. For example, feedback via mobile app can be timely because many individuals pay close attention to their smartphones, while in-home displays provide timely feedback only if the individual is in the vicinity when performing the associated action. Furthermore, timely feedback is helpful only if the behavior can be tracked with relative precision and if there are unique consequences from the behavior that can be incorporated into feedback.

\subsubsection{Frequency}

Frequency refers to the number of times feedback is delivered within a fixed period. The theoretical expectation is that higher frequency correlates with higher efficacy. Providing consistent reminders helps reinforce a message, thereby steering the individual internalize the information in the long-run. In the case of fostering behavioral change, habits are often stubborn in that individuals easily revert to old patterns. Higher frequency of feedback helps disrupt the undesired cue-behavior association long enough for the individual to develop new cue-behavior associations (i.e., habits). Studying household energy consumption, Fischer (2008) found that high-frequency feedback over a long duration was more effective than were alternative approaches; this was supported by Liu and Mukheibir (2018) in examining water consumption behaviors.

Literature on this topic, however, is inconclusive. No study directly compares the effect of varying frequencies of feedback while controlling for other factors (Hermsen et al., 2016). The findings referenced earlier were derived from comparisons of studies that had differing aims and contexts, including type of behavior targeted and duration of the intervention (Lally and Gardner, 2013). As such, it is difficult to conclude whether higher frequencies are more effective. Furthermore, frequency is difficult to assess in digital interventions (Liu and Mukheibir, 2018). In the case of 'push-based' feedback (occurring at a designated time), information is delivered but fails to elicit active engagement; the individual might fail to notice the feedback until later or simply choose to ignore it. On the other hand, for 'pull-based' feedback (available at any time), frequency reflects how often the information is updated or how often the individual accesses the information. It is prudent to note that the former fails to consider that information availability does not necessarily equate to information exposure, while the latter is dependent on selfdetermined feedback frequency (i.e., the user has control). 


\subsubsection{Duration}

Duration refers to the period between the first and last feedback item delivered; it refers specifically to the intervention rather than the effect of the intervention (i.e., the behavior that results). Cases used in studies of digital interventions are often limited in duration of the intervention, usually spanning only a few weeks to a few months. There is no consensus about optimal duration, as few studies have been conducted over a period longer than a year (Liu and Mukheibir, 2018). It is possible that longer duration may help ingrain long-term behavioral change, but there may also be decreasing marginal returns; further research is needed on the relationship between duration of interventions and duration of their effects. For example, individuals may grow accustomed to feedback and fail to notice it, thereby rendering the intervention less effective. Some studies find the possibility of 'rebound effects' in which the potency of interventions fades over time; for example, many studies demonstrate that water consumption habits tend to revert to their pre-intervention state (Liu and Mukheibir, 2018). Conversely, when feedback is renewed or reinstated, intervention potency persists for a longer period of time (Liu and Mukheibir, 2018). After an intervention is complete, it may be beneficial to provide digital feedback on an occasional basis to remind individuals to retain or reinforce newly adopted habits. Additional research is needed to determine the efficacy of such an approach.

\subsubsection{Disruptiveness}

Disruptiveness refers to the extent to which feedback positively disrupts the individual in the interest of provoking behavior change. For some interventions, disruptiveness may be strategically maximized to interrupt the individual while the undesired behavior is undertaken. This strategy is useful particularly in conjunction with concurrent feedback (i.e., that delivered in real-time), with the purpose of nudging the individual to change the behavior immediately.

Disruptiveness can be a contentious factor with significant trade-offs. Highly disruptive feedback risks triggering reactance or abandonment of a task (Hermsen et al., 2016). Recipients of feedback delivered in an aggressive or off-putting manner may react counterproductively, even

altering their behaviors to circumvent measurement and feedback. For example, the WaiTEK Shower Monitor is a device that continuously beeps after a fixed period of time, reminding an individual to leave the shower (Stewart et al., 2013). The device was designed to be audible across an entire dwelling unit - something that could provoke negative sentiment from the showering individual and other members of the household. This would be an unsustainable intervention, and in a worst-case scenario could provoke the showering individual to remove the device and take an even longer shower than before the intervention was attempted. 
To some extent, level of disruptiveness runs contrary to the quality of user experience: the more disruptive the feedback is, the worse the user experience may be. For some interventions, disruptiveness is a negative trait that must be minimized to protect user engagement. Hence, if a disruptive intervention is an essential element, it must be mindfully designed with consideration for user experience.

\subsection{Content}

\subsubsection{Feedback sign}

Content refers to the nature and format of information delivered to users, as categorized into feedback sign, information provision, and personalization. Feedback sign refers to whether the content is framed positively or negatively. Studies comparing the effect of rewards and penalties on engagement (Jain et al., 2012) and the effect of positive and negative feedback on work pace interruptions (Liu et al., 2014) found a greater effect for positive feedback than for negative. Moreover, the latter study found that negative feedback can increase performance but cause greater stress levels. In a meta-analysis of feedback signs, Hattie and Timperley (2007) found that positively framed feedback was more effective than negatively framed feedback.

Feedback sign is a salient issue when considering interventions related to sustainability. Examining the effect of political attitudes on pro-social environmental behavior like recycling, Coffey and Joseph (2013) found that politically conservative-identifying respondents were less likely to pay close attention to recycling than were liberal (non-conservative) respondents. The study also found that conservative respondents were more likely to believe that the news media overstate the threat of climate change. This is notable because feedback to induce proenvironmental behaviors should be sensitive to the predisposition of some individuals towards skepticism and resistance. Arguably, positive feedback is likelier to work better than negative feedback among such subgroups. However, level of experience and expertise of the user with a particular intervention can determine which feedback sign may be most appropriate. According to Fishbach et al. (2010) in a review of psychology research, positive feedback is more effective when the target is a novice in the given activity, whereas negative feedback is more effective when the target is experienced.

\subsubsection{Information provision}

The provision of information is hypothesized to be effective because individuals often have little idea about the extent or effects of their behaviors (e.g., how much water they use; Benzoni and Telenko, 2016; Attari, 2014; Beal et al., 2013). Informational feedback can inform individuals of the consequences of their actions, encouraging them to alter their habits. However, studies about the effect of information alone are unclear. Those finding provision of information effective 
include a study by Beal et al. (2013) identifying improvement in 'water literacy' through reduction in the discrepancy between actual and perceived water consumption. Additionally, Kurz et al. (2005) find that labels providing water-saving tips at points of consumption around an individual's home and garden led to water savings, while the provision of information leaflets or socially comparative feedback had no effect. On the other hand, Schultz et al. (2016) find that the provision of water-saving tips (without consumption feedback) showed no impact on water consumption, while the added use of descriptive norms (e.g., about similar households' usage) and aligned norms led to savings. In a study of high-consumption users, Seyranian et al. (2015) found that information (paradoxically) led to increased usage while use of social norm-based and personal identity-based framings led to decreased usage.

Other limitations of information provision include the possibility that individuals fail to understand the information provided, particularly concerning more technical aspects; this can depend on how the information is conveyed (e.g., use of graphics, analogies, and summaries). Further, individuals may not understand how to apply the information provided, underscoring the need to connect information and behaviors in the communication process. In several studies, information about how to use feedback to reduce consumption was shown to be effective (Fielding et al., 2013; Erickson et al., 2012; Froehlich et al., 2012; Ferraro et al., 2011).

\subsubsection{Personalization}

Variations in user characteristics and circumstances suggest that feedback should be personalized (Kaptein et al., 2012; Noar et al., 2011; Noar et al., 2007). Alternatively, individuals can be provided with the capacity to select information they find most interesting and relevant. Such tailoring encompasses use of negative, positive, or neutral feedback (i.e., feedback sign), offers social, historical, or normative comparisons (or no comparison at all), and can be done with increasing or decreasing levels of detail.

In a household where responsibility for resource consumption is shared, personalization of feedback can assign individual responsibility and transform role perceptions. For example, Wallenborn et al. (2011) argue that wasteful behavior in energy use can arise from differing role perceptions about cleanliness standards, and that varying levels of technical insight in families might lead to conflicts about feedback and related behavior. Kappel and Grechenig (2009) likewise find a household role-effect concerning information about water usage for showering. Such studies provide insight into how social interactions influence feedback effects. Feedback on performance can encourage discussion among household members, which may itself lead to behavior change, conflicts, or role clashes. Personalizing feedback to a specific type of behaviour may also be more effective than general feedback (e.g., nudging and providing tips; Froehlich et al., 2010; Winett et al., 1978). Additionally, algorithm-based recommender systems can be used to achieve greater levels of personalization (Rahim et al., 2020). 


\subsection{Integration}

According to Locke and Latham (2002), goals are translated into behavior in four ways: channeling attention, energizing efforts, encouraging persistence, and compelling actors to learn new skills and strategies. Regarding the latter, technology offers an opportunity to achieve the type of integration that allows actors to connect goals with behaviors and to learn new skills in doing so. For example, Koech and Gyasi-Agyei (2018) and King (2018) describe how technology can enhance the sophistication of water metering while integrating data about usage from various appliances. This illustrates to users the interconnectedness of consumption systems and underscores how conservation behavior in one aspect relates to the whole.

Additionally, the use of social media for integrating technology and measurement of water or energy usage is a potential intervention underexplored in the literature. This approach has promise in the sense that social media can shape pro-environmental behavior through the influence of networks and personal connections - particularly in gamification (competitions), comparisons, and public signals of commitment. Successfully integrating such measures into users' daily experiences is contingent on maintaining attention and avoiding a 'background noise' effect from unrelated information (Bentley et al., 2013; Jain et al., 2012; Wallenborn et al., 2011).

\subsection{Commitment}

The final determinant is commitment - the pledge made by a user to adhere to a behavior, expectation, or goal. Elements of commitment include details about the nature and degree of commitment, how long the party is accountable, and the degree of public visibility of the commitment (Gonzales and Aronson, 1988). Jacquemet et al. (2013) find in an experiment that participants who took an oath as a signal of commitment treated conditions of the activity as binding and were more inclined to be truthful. Regarding pro-environmental behavior, commitments and pledges as validated by signatures were found to increase recycling (Wang and Katzev, 1990) and commitments made 'publicly' led to reductions in energy consumption (Pallak and Cummings, 1976).

Commitment implies the possibility of either success or failure, with the committing party incentivized to signal success by following-through. Technology can thus provide mechanisms by which commitments and their fulfilment are made transparent to an audience, enabling more accountability should the individual choose to submit thereto. In particular, social media is an example of a venue where commitments are made as a signal of interest about certain issues. Examples are 'pledge systems' (Liu et al., 2017) that enable users to commit to particular actions, for example on matters of water consumption. 


\section{Recommendations}

This section outlines recommendations that correspond to the subsections of the previous section. First, there is no best practice for choice of technology channel. Other factors like cost of delivery and goals should take priority when identifying an appropriate technology channel. The benefits of selecting the proper channel include more efficient and effective alignment with policy goals and the ability to leverage digital advancements. Costs vary according to the technology chosen and include switching costs in the event that a given technology does not produce the desired results. Broader risks include the possibility of communicating misinformation to users and thereby confusing them or misguiding their actions (Nauges and Whittington, 2019).

Digital interventions rely most commonly on visual modality alone; indeed, this modality has the flexibility to communicate information in multiple forms using as much detail as desired. However, research has shown that there is no imperative to rely solely on visual modality. No modality has been proven more effective than others and no intervention needs necessarily to be restricted to only one modality. Thus, modality should be evaluated against intended goals and strategically chosen.

User experience is an evident determinant of engagement with and commitment to an intervention. It should be a high priority, with all forms of feedback having a suitable appearance and being user-friendly and intuitively understandable. A pilot version of a proposed intervention is recommended to measure and adjust user experience. The benefits of high-quality user experience are increased likelihood of engagement by users, while the costs are minimal and may include only the additional effort to design and update digital interfaces.

Feedback should be as timely as possible where feasible, suitable, and effective. There is no best practice for feedback frequency, and based on the research it should be a secondary consideration compared to other factors like timeliness. For example, frequency or a mix of frequencies might be one among multiple considerations for optimizing user engagement, in which water consumption data may be delivered (for example) twice per year but combined with water conservation tips on a monthly basis. The duration of the intervention should be as long as financially and technically feasible, provided that the intervention continues to maintain efficacy. One option is to begin with high levels of feedback engagement to change initial behaviors and subsequently maintain the intervention at a lower intensity (e.g., reminders once per year).

Regarding disruption, there is no best practice. The level of disruptiveness should be managed carefully, balanced between achieving the aims of the intervention and ensuring that the individual remains receptive to the intervention. The risk is that a level of disruption seen as 
unacceptable by the user may compel the user to disengage with the intervention and revert to previous behavior patterns. Regarding feedback sign, in general it has been shown that feedback should be framed positively. If content is unavoidably negative, a positive angle should be identified and paired with affirmative messaging. Further, if the intervention uses social norms (Koop et al., 2019) and/or historical information to 'shame' individuals into adopting certain behaviors, it should likewise be paired with affirmative messaging. According to Fishbach et al. (2010), however, negative feedback may be more effective among users who have longer experience with a particular activity or intervention.

Regarding information provision, information should be understandable and presented clearly. One option is to present water consumption in tangible terms (e.g., rather than in gallons used per day, presented in intuitively relatable terms: "amount of water consumed today $=1$ swimming pool"). Given that there is no clarity about whether and what type of information provision is effective, it may be prudent to provide a combination of information types. Examples are feedback for gamification, including that comparing current data with similar or proximate users, comparing historical data for the same user, and making general references to social norms based on data. Costs include the efforts to gather, analyze, and communicate data; broader risks include the perception that sensitive personal information about usage patterns is being made public.

Systems should personalize feedback approach where possible (e.g., delivery and content) based on individual motivation, characteristics, and living arrangements; this information can be collected from a survey. The more targeted the feedback, the more effective; examples are disaggregation of water consumption per appliance and assignment of water consumption per individual. At the same time, costs rise with increasing personalization of feedback, including those related to data gathering, processing, and repackaging. It is prudent to note that data privacy concerns attend the process of personalization, so data management procedures must be communicated clearly and developed collaboratively. Integrating feedback across various intervention types, where possible, is also recommended as a way to reach users throughout their daily activities. This requires a threshold level of coordination that may, however, prove to be costly or infeasible if interventions are hosted across disparate platforms.

Finally, systems should encourage commitment by providing technology-enabled platforms for making pledges and their fulfillment transparent. This can be integrated with real-time data collection to allow individuals to track their own progress on commitments, with an additional option to publicly share progress as desired. This approach also supports the gamification perspective while encouraging pro-environmental sentiments among users and observers of users' commitment progress. As with other interventions, the increasing digital sophistication, personalization, and interactiveness of the intervention raises costs. 


\section{Conclusion}

The technology revolution presents unprecedented opportunities to develop and improve feedback mechanisms for encouraging pro-environmental behaviors like recycling, energy conservation, and others. This article has examined five broad determinants of successful digital interventions, with a focus on water conservation. These include design, delivery, content, integration, and commitment. The article uses existing academic literature to provide theoretical support for and examples of each determinant, and from those findings outlines associated recommendations. In particular, the article argues that digital feedback capabilities must focus on multi-modality, maintain user-friendliness, take into account appropriate timing to highlight links with opportunities for behavior change, and do so using positive messaging where most effective. Digital innovations must also be applied to deepen capabilities for personalization, integrate technical systems and media platforms, and induce commitment and follow-through. Many of these aspirational capabilities will be realizable as technology continues to increase in sophistication, reach, and access. Each of these recommendations provides not only a template for policy action but also avenues for continued research. Indeed, as technical systems move towards the convergence of social media and practical systems like resource consumption, there exist further opportunities to draw on the concept of social signaling to understand proenvironmental behavior change.

At a higher level, the process of social and technological integration marks an important step in bridging the gap between technocratic policy interventions to sustainability challenges and the deep-seated behavioral determinants of resource degradation. According to Hartley and Kuecker (2020), smart water management risks inducing a behavioral 'moral hazard' in which technology "excuses society from a painful reckoning about the origins and perils of [unsustainable] habits" (p. 2) related to water usage. The novelty and convenience of smart technologies risk luring policymakers and the public into a belief that society can 'outrun' its own wasteful indulgences. While technological progress alone cannot resolve the perils of unsustainable behavior, digital interventions can provide some informational and communicative basis for raising awareness and encouraging fundamental shifts in attitudes, behaviors, and broader societal priorities. 


\section{References}

Attari, S. Z. (2014). Perceptions of water use. Proceedings of the National Academy of Sciences, 111(14), 5129-5134.

Beal, C. D., Stewart, R. A., \& Fielding, K. (2013). A novel mixed method smart metering approach to reconciling differences between perceived and actual residential end use water consumption. Journal of Cleaner Production, 60, 116-128.

Bentley, F., Tollmar, K., Stephenson, P., Levy, L., Jones, B., Robertson, S., Price, E., Catrambone, R. and Wilson, J. (2013). Health Mashups: Presenting statistical patterns between wellbeing data and context in natural language to promote behavior change. ACM Transactions on Computer-Human Interaction (TOCHI), 20(5), pp.1-27.

Benzi, F., Anglani, N., Bassi, E., \& Frosini, L. (2011). Electricity smart meters interfacing the households. IEEE Transactions on Industrial Electronics, 58(10), 4487-4494.

Benzoni N., Telenko C. (2016) A Review of Intervention Studies Aimed at Domestic Water Conservation. In: Marcus A. (eds) Design, User Experience, and Usability: Novel User Experiences. DUXU 2016. Lecture Notes in Computer Science, vol 9747. Springer.

Braga, B., \& Kelman, J. (2020). Facing the challenge of extreme climate: the case of Metropolitan Sao Paulo, International Journal of Water Resources Development, 36:2-3, 278-291, DOI: 10.1080/07900627.2019.1698412

Braverman, J. (2008). Testimonials Versus Informational Persuasive Messages: The Moderating Effect of Delivery Mode and Personal Involvement. Communication Research, 35(5), 666-694.

Brent, D. A., Cook, J. H., \& Olsen, S. (2015). Social comparisons, household water use, and participation in utility conservation programs: Evidence from three randomized trials. Journal of the Association of Environmental and Resource Economists, 2(4), 597627.

Chatzigeorgiou, I. M., \& Andreou, G. T. (2021). A systematic review on feedback research for residential energy behavior change through mobile and web interfaces. Renewable and Sustainable Energy Reviews, 135, 110187. 
Coffey, D. J., \& Joseph, P. H. (2013). A polarized environment: The effect of partisanship and ideological values on individual recycling and conservation behavior. American Behavioral Scientist, 57(1), 116-139.

Cominola, A., Giuliani, M., Piga, D., Castelletti, A., \& Rizzoli, A. E. (2015). Benefits and challenges of using smart meters for advancing residential water demand modeling and management: A review. Environmental Modelling \& Software, 72, 198-214.

Consolvo, S., McDonald, D. W., \& Landay, J. A. (2009). Theory-driven design strategies for technologies that support behavior change in everyday life. In Proceedings of the SIGCHI Conference on Human Factors in Computing Systems (pp. 405-414). ACM.

Darby, S. (2006). The effectiveness of feedback on energy consumption. In A Review for DEFRA of the Literature on Metering, Billing and direct Displays, 486.

Datta, S., Miranda, J. J., Zoratto, L., Calvo-González, O., Darling, M., \& Lorenzana, K. (2015). A behavioral approach to water conservation: evidence from Costa Rica. The World Bank.

Ehrhardt-Martinez, K., Donnelly, K. A., \& Laitner, S. (2010). Advanced metering initiatives and residential feedback programs: a meta-review for household electricity-saving opportunities. Washington, DC: American Council for an Energy-Efficient Economy.

Erickson, T., Li, M., Kim, Y., Deshpande, A., Sahu, S., Chao, T., Sukaviriya, P. and Naphade, M. (2013). The Dubuque electricity portal: evaluation of a city-scale residential electricity consumption feedback system. In Proceedings of the SIGCHI Conference on Human Factors in Computing Systems (pp. 1203-1212).

Erickson, T., Podlaseck, M., Sahu, S., Dai, J. D., Chao, T., \& Naphade, M. (2012). The Dubuque water portal: evaluation of the uptake, use and impact of residential water consumption feedback. In Proceedings of the SIGCHI Conference on Human Factors in Computing Systems (pp. 675-684).

Ferraro, P. J., \& Price, M. K. (2013). Using nonpecuniary strategies to influence behavior: evidence from a large-scale field experiment. Review of Economics and Statistics, 95(1), 64-73.

Ferraro, P. J., Miranda, J. J., \& Price, M. K. (2011). The persistence of treatment effects with norm-based policy instruments: evidence from a randomized environmental policy experiment. American Economic Review, 101(3), 318-22. 
Fielding, K. S., Spinks, A., Russell, S., McCrea, R., Stewart, R., \& Gardner, J. (2013). An experimental test of voluntary strategies to promote urban water demand management. Journal of Environmental Management, 114, 343-351.

Fischer, C. (2008). Feedback on household electricity consumption: a tool for saving energy? Energy Efficiency, 1(1), 79-104.

Fishbach, A., Eyal, T., \& Finkelstein, S. R. (2010). How positive and negative feedback motivate goal pursuit. Social and Personality Psychology Compass, 4(8), 517-530.

Froehlich, J., Findlater, L., Ostergren, M., Ramanathan, S., Peterson, J., Wragg, I., Larson, E., Fu, F., Bai, M., Patel, S. and Landay, J.A., (2012). The design and evaluation of prototype eco-feedback displays for fixture-level water usage data. In Proceedings of the SIGCHI conference on human factors in computing systems (pp. 2367-2376).

Froehlich, J., Findlater, L., \& Landay, J. (2010). The design of eco-feedback technology. In Proceedings of the SIGCHI Conference on Human Factors in Computing Systems (pp. 1999-2008). ACM.

Fujii, S. (2006). Environmental concern, attitude toward frugality, and ease of behavior as determinants of pro-environmental behavior intentions. Journal of Environmental Psychology, 26, 262-268.

Gonzales, M.H. and Aronson, E. (1988). Using social cognition and persuasion to promote energy conservation: a quasi-experiment. Journal of Applied Social Psychology, 18(12), p. 1049-1066.

Gurung, T. R., Stewart, R. A., Sharma, A. K., \& Beal, C. D. (2014). Smart meters for enhanced water supply network modelling and infrastructure planning. Resources, conservation and recycling, 90, 34-50.

Hall, A. K., Cole-Lewis, H., \& Bernhardt, J. M. (2015). Mobile text messaging for health: a 984 systematic review of reviews. Annual Review of Public Health, 36, 393.

Hattie, J., \& Timperley, H. (2007). The power of feedback. Review of Educational Research, 77(1), 81-112.

Hermsen, S., Frost, J., Renes, R. J., \& Kerkhof, P. (2016). Using feedback through digital technology to disrupt and change habitual behavior: A critical review of current literature. Computers in Human Behavior, 57, 61-74. 
Hoggan, E., \& Brewster, S. A. (2010). Crosstrainer: testing the use of multimodal interfaces in situ. In Proceedings of the SIGCHI Conference on Human Factors in Computing Systems (pp. 333-342). ACM.

Hoggan, E., Crossan, A., Brewster, S. A., \& Kaaresoja, T. (2009). Audio or tactile feedback: which modality when?. In Proceedings of the SIGCHI Conference on Human Factors in Computing Systems (pp. 2253-2256). ACM.

Jacquemet, N., Joule, R. V., Luchini, S., \& Shogren, J. F. (2013). Preference elicitation under oath. Journal of Environmental Economics and Management, 65(1), 110-132.

Jain, R. K., Taylor, J. E., \& Peschiera, G. (2012). Assessing eco-feedback interface usage and design to drive energy efficiency in buildings. Energy and Buildings, 48, 8-17.

Johnson, D., Horton, E., Mulcahy, R., \& Foth, M. (2017). Gamification and serious games within the domain of domestic energy consumption: A systematic review. Renewable and Sustainable Energy Reviews, 73, 249-264.

Kappel, K., \& Grechenig, T. (2009, April). "Show-me" water consumption at a glance to promote water conservation in the shower. In Proceedings of the 4th international conference on persuasive technology (pp. 1-6).

Kaptein, M., De Ruyter, B., Markopoulos, P., \& Aarts, E. (2012). Adaptive persuasive systems: a study of tailored persuasive text messages to reduce snacking. ACM Transactions on Interactive Intelligent Systems (TiiS), 2(2), 1-25.

King, A. (2018). Tricky Leaks: New Plumbing Technology. Available online: https://plumbingconnection.com.au/tricky-leaks-new-plumbing-technology/

Koech, R.; Gyasi-Agyei, Y.; Randall, T. (2018). The evolution of urban water metering and conservation in Australia. Flow Measurement and Instrumentation, 62, 19-26.

Konopko, J. (2016). Big data solutions for smart grids and smart meters. In Machine Intelligence and Big Data in Industry (pp. 181-200). Springer, Cham.

Koop, S. H. A., Van Dorssen, A. J., \& Brouwer, S. (2019). Enhancing domestic water conservation behaviour: A review of empirical studies on influencing tactics. Journal of Environmental Management, 247, 867-876. 
Kurz, T., Donaghue, N., \& Walker, I. (2005). Utilizing a Social-Ecological Framework to Promote Water and Energy Conservation: A Field Experiment 1. Journal of Applied Social Psychology, 35(6), 1281-1300.

Hartley, K., \& Kuecker, G. (2020). The moral hazards of smart water management. Water International, 45(6), 1-9.

Kenney, D. S., Goemans, C., Klein, R., Lowrey, J., \& Reidy, K. (2008). Residential water demand management: lessons from Aurora, Colorado 1. JAWRA Journal of the American Water Resources Association, 44(1), 192-207.

Larson, K., \& Picard, R. (2005). The Aesthetics of Reading. In Human-Computer Interaction Consortium Conference, Snow Mountain Ranch, Fraser, Colorado.

Legault, L., Bird, S., Powers, S. E., Sherman, A., Schay, A., Hou, D., \& Janoyan, K. (2020). Impact of a motivational intervention and interactive feedback on electricity and water consumption: a smart housing field experiment. Environment and Behavior, 52(6), 666692.

Lieberman, J., \& Breazeal, C. (2007). TIKL: Development of a Wearable Vibrotactile Feedback Suit for Improved Human Motor Learning. IEEE Transactions on Robotics, 919-926.

Liu, A., \& Mukheibir, P. (2018). Digital metering feedback and changes in water consumptionA review. Resources, Conservation and Recycling, 134, 136-148.

Liu, A., Giurco, D., Mukheibir, P., Mohr, S., Watkins, G., \& White, S. (2017). Online water-use feedback: household user interest, savings and implications. Urban Water Journal, 14(9), 900-907.

Liu, Y., Jia, Y., Pan, W., \& Pfaff, M. S. (2014). Supporting task resumption using visual feedback. In Proceedings of the 17th ACM conference on Computer supported cooperative work \& social computing (pp. 767-777).

Locke, E. \& Latham, G. (2002). Building a Practically Useful Theory of Goal Setting and Task Motivation, a 35-Year Odyssey. American Psychologist 57, 9(2002), 705-717.

MacRae Jr, D., \& Whittington, D. (1988). Assessing preferences in cost-benefit analysis: Reflections on rural water supply evaluation in Haiti. Journal of Policy Analysis and Management, 7(2), 246-263. 
Monks, I., Stewart, R. A., Sahin, O., \& Keller, R. (2019). Revealing unreported benefits of digital water metering: Literature review and expert opinions. Water, 11(4), 838.

Morganti, L., Pallavicini, F., Cadel, E., Candelieri, A., Archetti, F., \& Mantovani, F. (2017). Gaming for Earth: Serious games and gamification to engage consumers in proenvironmental behaviours for energy efficiency. Energy Research \& Social Science, 29, 95-102.

Mudumbe, M. J., \& Abu-Mahfouz, A. M. (2015). Smart water meter system for user-centric consumption measurement. In 2015 IEEE 13th International Conference on Industrial Informatics (INDIN) (pp. 993-998). IEEE.

Nakajima, T., \& Lehdonvirta, V. (2013). Designing motivation using persuasive ambient mirrors. Personal and Ubiquitous Computing, 17(1), 107-126.

Nauges, C., \& Whittington, D. (2019). Social norms information treatments in the municipal water supply sector: some new insights on benefits and costs. Water Economics and Policy, 5(03), 1850026.

Nilsson, A., Wester, M., Lazarevic, D., \& Brandt, N. (2018). Smart homes, home energy management systems and real-time feedback: Lessons for influencing household energy consumption from a Swedish field study. Energy and Buildings, 179, 15-25.

Noar, S. M., Grant Harrington, N., Van Stee, S. K., \& Shemanski Aldrich, R. (2011). Tailored health communication to change lifestyle behaviors. American Journal of Lifestyle Medicine, 5(2), 112-122.

Noar, S. M., Benac, C. N., \& Harris, M. S. (2007). Does tailoring matter? Meta-analytic review of tailored print health behavior change interventions. Psychological Bulletin, 133(4), 673.

Owen, D. A. L. (2018). Smart water technologies and techniques: data capture and analysis for sustainable water management. John Wiley \& Sons.

Pallak, M.S., Cummings, W. (1976). Commitment and voluntary energy conservation. Personality and Social Psychology Bulletin 2(1), 27-30.

Quinn, J. M., Pascoe, A., Wood, W., \& Neal, D. T. (2010). Can't control yourself? Monitor those bad habits. Personality and Social Psychology Bulletin, 36(4), 499-511. 
Quintal, F., Pereira, L., \& Nunes, N. J. (2012). A long-term study of energy eco-feedback using non-intrusive load monitoring. Persuasive Technology, 49.

Rahim, M. S., Nguyen, K. A., Stewart, R. A., Giurco, D., \& Blumenstein, M. (2020). Machine Learning and Data Analytic Techniques in Digital Water Metering: A Review. Water, 12(1), 294.

Rathore, M. M., Ahmad, A., Paul, A., \& Rho, S. (2016). Urban planning and building smart cities based on the internet of things using big data analytics. Computer Networks, 101, 63-80.

Rodgers, J., \& Bartram, L. (2011). Exploring ambient and artistic visualization for residential energy use feedback. IEEE Transactions on Visualization and Computer Graphics, 17(12), 2489-2497.

Rodina, L. (2019). Water resilience lessons from Cape Town's water crisis. Wiley Interdisciplinary Reviews: Water, 6(6), e1376.

Schultz, P. W., Messina, A., Tronu, G., Limas, E. F., Gupta, R., \& Estrada, M. (2016). Personalized normative feedback and the moderating role of personal norms: A field experiment to reduce residential water consumption. Environment and Behavior, 48(5), 686-710.

Seyranian, V., Sinatra, G. M., \& Polikoff, M. S. (2015). Comparing communication strategies for reducing residential water consumption. Journal of Environmental Psychology, 41, 81-90.

Sonderlund, A. L., Smith, J. R., Hutton, C., Kapelan, Z., \& Savic, D. (2016). Effectiveness of smart-meter based consumption feedback in curbing household water use: Knowns and unknowns. Journal of Water Resources Planning and Management.

Stewart, R. A., Willis, R. M., Panuwatwanich, K., \& Sahin, O. (2013). Showering behavioural response to alarming visual display monitors: longitudinal mixed method study. Behaviour \& Information Technology, 32(7), 695-711.

Tractinsky, N., Katz, A. S., \& Ikar, D. (2000). What is beautiful is usable. Interacting with Computers, 13(2), 127-145.

Tuch, A. N., Presslaber, E. E., Stöcklin, M., Opwis, K., \& Bargas-Avila, J. A. (2012). The role of visual complexity and prototypicality regarding first impression of websites: Working 
towards understanding aesthetic judgments. International Journal of Human-Computer Studies, 70(11), 794-811.

Wallenborn, G., Orsini, M., \& Vanhaverbeke, J. (2011). Household appropriation of electricity monitors. International Journal of Consumer Studies, 35(2), 146-152.

Wang, T. and Katzev, R. (1990). Group commitment and resource conservation: two field experiments on promoting recycling. Journal of Applied Social Psychology 20(4), 265275.

Warnock, D., McGee-Lennon, M., \& Brewster, S. (2011). The role of modality in notification performance. In Human-Computer Interaction-INTERACT 2011 (pp. 572-588). Springer Berlin Heidelberg.

Winett, R. A., Kagel, J. H., Battalio, R. C., \& Winkler, R. C. (1978). Effects of monetary rebates, feedback, and information on residential electricity conservation. Journal of Applied Psychology, 63(1), 73.

Wood, W., \& Neal, D. T. (2009). The habitual consumer. Journal of Consumer Psychology, 19, 579-592. 